\title{
SOCIAL-PEDAGOGICAL PERSPECTIVES OF THE DEVELOPMENT OF PRIMARY SCHOOLCHILDREN'S ABILITY OF SELF-ESTEEM
}

\section{Abstract}

The article discusses methodological matters related to the ability of self-esteem in the primary school age. The factors for and methods of the development of the ability of self-esteem in the teaching process as well as the potential of school subjects have been analysed. Surveys have been conducted among teachers concerning their engagement in the development of schoolchildren's self-esteem and a sample lesson has been designed for developing the ability of self-esteem at school.

Keywords: primary schoolchildren, self-esteem, self-realisation, self-awareness, school environment, social norm, motive, appraisal, performance, strengths and weaknesses.

\section{Introduction}

At primary school, age determines children's behaviour and attitude towards the surrounding environment and events. The motivation to act independently may already develop at this age. It is the first step towards the awareness of one's abilities, for which the family and school may bear responsibility. It is important that at school and in the family the child be accepted as an independent person, who perceives, is aware of and understands the events taking places around, hence grown-ups should not impose their will on the child. Children should be allowed to analyse and evaluate the consequences of their actions as well as draw conclusions themselves. In this case, they will be aware of their actions and be responsible for them. Moreover, they will gradually be able to differentiate their opinion from others' perspectives, consider others' viewpoints, agreeing or disagreeing with them and will not be obstinate or aggressive. If parents are careful and caring, support and praise their children and teach them to solve problems arising in various situations, then they will grow up with a high sense of self-esteem and will be confident of their abilities. Nevertheless, this ability starts to systematically develop at pre-school and general education institutions. When raising self-esteem at school, it is important to consider primary schoolchildren's age, their individual, psychological and physiological peculiarities, apply diverse methods and activities for that purpose, take into account their 
possible impact and social-psychological consequences.

\section{Discussion}

Collins (2009, p. 3) defines self-esteem as a child's personal evaluation, "the difference between the self-image and the ideal self." Children with high self-esteem strive for achieving the "ideal self" by improving their competences, attitudes and how they behave. In contrast, children with low self-esteem find it difficult to achieve these aims and thus fail to reach this "ideal self" (Collins, 2009). This perception may be based on Rosenberg's (1979) definition of self-esteem as an attitude to one's worthiness or value as a person, "a positive or negative attitude toward a particular object, namely, the self" (1979, p. 30).

Self-esteem starts developing in childhood and is influenced by the family (Ghilay and Ghilay, 2015) as well as the people who surround the child. Various factors, events and phenomena are also vital in this process. It is an awareness of one's actions, characteristics and abilities; an evaluative attitude towards them as well as perceptions of one's own identity. According to Burnett (1994, p.165), it is a "Global cognitive and affective/feeling orientation that focuses on how an individual feels about him or herself as a person." It is thus an opinion of one's own abilities or in other words, it shows what criteria or values guide a person when evaluating their actions. Self-esteem is an important factor for the development of a personality; it gives a chance of choice in various life situations, determines future perspectives, ambitions and the motivation to achieve them. The ability of self-esteem allows to control, oversee and improve one's actions, set vital goals and implement them. It is an insight, self-analysis and a reflection on one's own abilities and strengths. However, the thoughts of what one wants, what is possible and what one is able of are always in clash. In some cases, people overestimate their abilities, by aiming at more than they can achieve or vice versa.

A person's self-esteem develops over a lifespan and is shaped through various life experiences (Orth and Robins, 2019). It means that in various stages of life it is influenced by life circumstances and other factors such as cultural, racial, ethnic and economic factors as well as social and self-values, parenting style and birth order (Mruk, 2006), among other things. It changes when a person deals with the society, performs certain functions, compares oneself with others, enjoys success and encounters failures, gets appraisal and reprimand, realises the results of his or her actions and their social significance. Self-esteem develops thanks to the analysis of the past actions, assessment of the present situation and the planning of the future actions. It is an incentive for development: Before undertaking new actions, a person estimates his or her abilities and after fulfilling them compares the compliance of the real abilities with the implemented action. By comparing oneself to others 
in certain situations it is possible to discover new attributes, features and qualities in oneself and vice versa, one can become aware of certain qualities missing in oneself. This encourages a person to acquire certain attributes or reject negative performance and undesirable qualities. Ideals and norms in the society and others' qualities can serve as comparison criteria. Self-esteem is thus a socially conditioned process, which depends on the norms adopted by a society or a social group as well as on the criteria that are accepted or rejected. Self-esteem is often accompanied by emotions, but it is not a mere feeling, as certain values underlie it with cognitive and emotional as well as mental and sensory components.

Thanks to the ability of self-esteem a person can improve his or her social status, achieve success, and forge his or her ideal self. It encompasses physical, behavioural, psychological and social self-expressions, which are related to one's identity and selfrealisation. Self-esteem can be objective when a person's opinion of themselves coincides with the reality. However, social relationships often interfere with this ability, as it sometimes develops not as a result of assessing one's real abilities, but based on others' attitudes, which may not coincide with a person's real abilities. It is, after all, a perception rather than a reflection of reality (Baumeister et al., 2003). The level of selfesteem impacts a person's performance.

External factors as well as incomplete knowledge and competences, fears in the childhood, negative emotions, inferiority complex, inability to appropriately assess one's strengths, the state of being misunderstood, rejected and disliked, failed relationships with peers and other factors result in the development of low self-esteem. Children with low self-esteem often have parents who do little or nothing with them, ignore their interests, opinions and strife for independence. These children's parents may fail to emotionally bond with them. As a result, children experience loneliness and develop a feeling of impotence. When a child is in the centre of attention, his or her strengths and weaknesses are assessed objectively. Where children sense trust, their self-esteem develops properly. Low self-esteem lowers the level of a person's social demands, develops a sense of uncertainty about one's abilities and limits goal setting and perspectives. Such a feeling of low confidence can be accompanied by negative emotions, inner conflicts and complexes.

The age between six to seven and ten to eleven years is a crucial period for adopting to the new school environment, for integrating, cooperating with others as well as for being aware of one's rights and duties. It is a period for the growth of social selfawareness, and it is important that matters related to objectively assessing one's abilities, 
the sense of personal dignity, fair and unbiased attitude, tolerance and kindness towards others become topics of discussion at this age at school. At this age, it is essential for a child to be an accepted and full member in a group. The quality of interpersonal relationships, teachers', classmates' and peers' attitude as well as learning and extracurricular environments, the content of tasks and the targeted pedagogical impact play a crucial role. Educational achievements, teaching and upbringing methods such as praise, talks, competitions, debates, discussions, role plays, which encourage selfexpression, play a decisive role in developing the ability of self-esteem. The child gradually realises his or her place and role in the new relationships thanks to selfawareness. However, when the abilities are not properly valued, the ability of self-esteem does not develop appropriately, the child loses trust in his or her own abilities, gets easily offended, becomes aggressive, uncommunicative, self-centred, indifferent and makes no attempts at finding out which attributes are responsible for failures. Collins (2009) also supports this view by pointing out that children's self-esteem is based on people's opinion of them and how they value the child. If praised, they will feel good about themselves and a critical opinion of them will make them feel worthless (Collins, 2009).

At the primary school age, children try to establish themselves and solve tasks in various ways such as in play, at study and work. Focusing on difficulties and failures and having a lack of confidence in their competences, children sometimes find it challenging to establish friendly relationships, which may damage their sense of self-esteem. Primary schoolchildren may focus on a task with difficulty; parents' or teachers' motivating or praising words, gestures or glance can become a positive stimulus for them. When the grown-ups underestimate children's abilities, they can become reclusive and uncommunicative and can develop a low sense of self-esteem.

In the primary school environment, children begin to gradually be aware of their rights, try to establish themselves and demonstrate their abilities, be in the centre of attention, get encouragement and stand out in the group. They freely communicate with adults and peers, manage to formulate full and well-thought sentences to answer questions, correct peers' answers and express themselves freely. These features play a decisive role in shaping self-esteem. When discussing the relationship between high and low self-esteem and school performance, Baumeister et al. (2003) point out that high selfesteem can contribute to good performance at school. It gives the confidence to set goals, overcome difficulties and enjoy success rather than suffer from feelings of incompetence and self-doubt that low self-esteem can cause (Baumeister et al., 2003).

Excessive praise or reprimand and humiliation are damaging for a child's self- 
esteem. The criteria, traditions and values adopted in the family are decisive, which can impact children's attitude towards their success and failures at school. Sometimes children are praised by the family members without any grounds; however, the evaluation outside the family may not always coincide with that given by the family. That contrast may be emotionally disturbing. The wrong or inflated praise of abilities and competences can in the future negatively reflect on the whole life. Hence, it is essential to consider children's emotional and behavioural features, character, nature, sensitiveness, communicativeness, tolerance level and ability of compassion.

\section{Materials and methods}

In order to collect data on the development of primary schoolchildren's self-esteem, an online survey has been conducted among 86 primary school teachers from general education schools in the Republic of Armenia. The teachers were supposed to choose a response for each question and statement in the survey questionnaire.

To the question "Do you encourage schoolchildren to independently evaluate their performance?" $25.6 \%$ of the teachers have chosen a positive answer, $30.2 \%$ of them have chosen "according to the situation" and $44.2 \%$ of the surveyed "never do it." This result shows that most of the surveyed teachers do not encourage the schoolchildren to analyse their actions and realise positive or negative, acceptable or rejectable aspects of their performance, which may play a great role in the development of children's selfesteem.

Only $27.9 \%$ of the teachers have chosen a positive response to the question "Do you create situations that encourage expression of motives for self-esteem?" $32.6 \%$ of the teachers "do it sometimes" and $39.5 \%$ of them "never do it."

To the statement "When you reprimand a schoolchild for a certain act, he or she..." $24.4 \%$ of the teachers have chosen the answer "complains, protests," $61.6 \%$ of them have chosen "keeps silent, does not openly express complaint" and $14 \%$ of the questioned - "requires explaining the reasons." The data are concerning, as they show that most of the schoolchildren silently agree, which in various life situation can discourage them to analyse their performance, realise the positive or negative consequences of their actions and evaluate them, by probably thinking that the teacher or the other person is always right.

The statement "When you praise the schoolchild for an action or quality, he or she..." has yielded the following answers: $43.1 \%$ of the teachers have chosen "becomes more confident," $39.5 \%$ of the questioned have selected "always tries to be praised" and 17.4 $\%$ of them - "at first becomes motivated, then turns indifferent." Appraisal is at this age 
an important factor and the teachers' answers show how effective it is to praise when there are grounds for it.

"What do you find important for developing the ability of self-esteem among the schoolchildren?" question has received the following answers: $20.9 \%$ of the surveyed have chosen the answer "the role of the family since childhood," $37.2 \%$ of the teachers have found "the role of the teachers and the factor of motivation" important, $18.6 \%$ of them have underscored "interpersonal communication and active relationships" and 23.3 $\%$ of the questioned have considered "the use of teaching materials aimed at selfawareness" relevant. This shows that most of the teachers consider their role in developing the schoolchildren's ability of self-esteem important.

To the question "Which educational methods mostly contribute to the development of self-esteem?" $48.8 \%$ of the surveyed teachers have considered "appraisal," $23.3 \%$ of them - "good example," $16.3 \%$ of the teachers - "competition" and $11.6 \%$ of the questioned - "pedagogical demand" as a contributing factor. The collected data show that according to the teachers, appraisal is an important factor in developing self-esteem whereas pedagogical demand may not be an efficient means for that purpose.

Among the answers to the question "What reaction do you show to an undesirable action by a schoolchild?" $9.3 \%$ of the teachers have chosen "I ignore," $20.9 \%$ of the questioned have selected "I encourage them to evaluate their actions themselves," 27.9 $\%$ of the questioned teachers have preferred "I make comparisons with their classmates" and $41.9 \%$ of them have underscored "I reprimand with words or my glance." It is concerning that only $20.9 \%$ or 18 teachers encourage the children to evaluate their work, the majority or 36 teachers reprimand with words or glance, which may not have a strong pedagogical impact from the perspective of developing the ability of self-esteem.

To the question "Do you design lessons and do activities with the schoolchildren that are aimed at developing their self-esteem?" only $7.2 \%$ of the questioned have chosen a positive answer, $28.2 \%$ of the teachers occasionally do it and $64.6 \%$ of them have never done it.

A summary of the survey results shows that the development of primary schoolchildren's self-esteem requires serious work. Most of the teachers do not have a unified attitude to this question or hardly do any activities in class for developing schoolchildren's self-esteem, hence it is necessary to prioritise this approach during teachers' vocational training courses as well as include more topics related to selfawareness and self-esteem in the curricula.

The content of school subjects, extracurricular events and methodological 
complexes contribute to the development of primary schoolchildren's ability of selfesteem. The potential of study topics as well as the use of relevant methods, means and ways can be quite effective for developing the ability of self-esteem. Since mother tongue and foreign languages contribute to communication, cognition, expression of thoughts, emotions and feelings, they can be useful means for developing the ability of self-esteem. Discussions about study topics, literary works, films, animations, deeds of real-life heroes, distinction between positive and negative features of familiar characters and expression of an evaluative attitude will develop in children notions about ideals, values, norms, the positive and the negative as well as what is acceptable and rejectable, gradually developing an evaluative attitude towards their own actions. It is also useful to apply debate elements, encouraging children to develop their own opinions and express them freely about phenomena and the deeds of a character. Role plays can also contribute to the development of the ability of self-esteem: By choosing a character and trying to represent them, the children can in some way identify with them, try to demonstrate the features of the character by condemning, accepting or rejecting them. Evaluating their qualities as well as comparing or contrasting themselves with the chosen character also naturally develop in children.

"Me and the Surrounding World" integrated school subject at primary school not only aims at imparting knowledge about natural phenomena and elements in the surrounding world but also at developing self-awareness, responsible behaviour, self-management, self-control, time-management, acknowledgement of own duties and the forging of relationships with people. Mathematics is also a means of learning about the world, developing interests and critical thinking skills; it is an important way of being quick and flexible in decision-making and making judgements, hence mathematics lessons may allow children to recognise, compare and evaluate own abilities and become aware of the abilities that will help achieve success. Music, fine arts, technology and physical education lessons also greatly contribute to the development of self-esteem. They aim at emotional, mental and physical development and acknowledgement of own strengths and drawbacks; they encourage self-expression, support creative thinking and imagination. By improving motor skills, children acquire courage and self-confidence as well as acknowledge the importance of their health, harmony, body agility and symmetry, which may help to objectively assess their own abilities.

After accomplishing various tasks, it is useful to encourage children to express their opinions, discuss how they carried them out, which qualities helped them achieve good results, which quality still misses and what they would still like to achieve. It is advisable 
to gradually teach children to set criteria or certain desirable qualities for carrying out certain tasks, which will help them get a perspective of their real abilities and competences and develop motives for acquiring better qualities. It is, however, important to consider that desirable qualities do not always have to be related to study achievements and success at school; they should concern interpersonal and intercultural communication, acknowledgement of physical and psychological abilities, efficient time management, behaviour, social, aesthetical, ethical and other competences.

The following sample lesson could be an example of developing schoolchildren's ability of self-esteem in the $4^{\text {th }}$ grade:

Lesson topic: A. Parsamyan's fairy tale "Magic Brush" (Gyurjinyan \& Hekekyan, 2012)

Main theme: Self-awareness, self-esteem.

Other themes: Readiness to help, decision-making, ingenuity, kindness, communication, sense of time, agility, self-organisation, self-presentation.

Expected outcomes:

The schoolchildren should

$>\quad$ be able to present themselves, describe their appearance, hobbies and wishes, talk about the people around themselves, interpret the similarities and differences between themselves and their friends, communicate verbally and in written form, cooperate.

be aware of the consequences of their actions, evaluate their abilities, express opinions, feelings and wishes, strive for self-awareness, be aware of their uniqueness as well as their strengths and weaknesses.

$>\quad$ self-organise in various situations, make decisions, manage time properly, distinguish priorities, be able to navigate quickly, take the initiative, control own words and actions.

respect others, show empathy and such qualities, which will help make useful decisions in various situations of life.

The story is about a boy who has received New Year gifts, among them pencils and a brush. It turns out that it is not a common, but a magic brush. Whatever the boy paints, will come to life, but only on the first day of the New Year. The boy quickly tries out the brush: He touches the dry grapevine with it, which will grow in spring. He paints a kennel for the homeless dog, which becomes real, the broken glass becomes new, when he paints it. At the end of the day, he tries to paint a boat for himself, but he remembers the old blind neighbour and hurries to touch his eyes with the brush before it loses its magic. 
In the initial phase of the lesson, the popcorn method is used. The schoolchildren stand up, say their names and surnames, name their favourite activities and wishes.

In the phase of meaning perception, the prediction chart method is applied: The schoolchildren read a passage from the story in pairs, then they predict what happens next. With the help of the round robin discussion strategy, the main meaning of the story is explained.

Five groups are then formed, which carry out a cooperative task. Each group gets a worksheet with tasks:

Task 1: Fill in the T-chart, by writing down and evaluating the boy's actions on one side and mentioning what he could do for himself that he did not do on the other side of the chart.

Task 2: Divide the group into two subgroups, one of which points out positive actions and wishes and the other one - what qualities are necessary for realising them.

Task 3: Express wishes that the boy could realise with the help of the brush. Each member orders them according to their level of importance for themselves, then everyone's version is discussed in the group, they choose the one most favoured by everyone and in the end a scale of wishes is created according to their importance and usefulness.

Task 4: Retell the story by presenting your favourite character in it, change their actions, evaluate them and think of another ending.

Task 5: Think of a hero in a literary work, film or from real life that you would like to identify with, remember which actions or qualities you liked most and explain why.

At the end of the activity, one member from each group presents the accomplished task, the groups ask each other questions and sum up the results.

During the break, children print their fingerprints in their worksheets, compare them and make sure that they are unique. This activity motivates the children and encourages them to think and realise that they are all unique.

During the weighing-up phase, the quadrans method is used: the blackboard is divided into four parts and the schoolchildren answer the following written questions:

What impression did you get while reading the fairy tale? Which song did it remind of, what would you paint, what colour has the story?

What interested you most, what did you learn that you would apply in life?

What feelings did you experience, what did you realise, describe your feelings?

Point out three actions for which you will be praised highly at school.

The tree of wishes method helps to sum up the main and other ideas in the fairy 
tale, the keywords are pointed out, the children name their wishes or dreams by saying what qualities are necessary for realising them, which are then painted as big and small tree branches. Then the children write down their wishes and desirable qualities on sticky papers and stick them on the blackboard by creating a Wall of Wishes.

At the end of the lesson, creative tasks are assigned as homework (write an essay, paint, create something by using various materials, etc.). The following topics can be assigned:

What kind of person I am and how I would like to be.

What I want and what I can.

Letter from the future: How I imagine myself after several years.

Read "The Ugly Duckling" fairy tale by Hans Christian Andersen and explain what you learned from it.

A descriptive assessment is applied according to the following criteria: the schoolchildren's participation, active engagement, correct and persuasive speech, involvement in the task implementation, ability to finish in time, presentation of the results, ability to listen to others, ability to be cooperative and ability of self-esteem.

\section{Conclusion}

Primary school age is a vital period for the development of self-awareness, selfmanagement, acknowledgement of own actions and sense of responsibility. It is important that at this age in all forms of activities the evaluation of one's abilities and trust in one's strengths be prioritised. Self-esteem determines how efficiently a child socially adapts to and integrates into the surrounding world; it controls behaviour and has a direct impact on a child's emotions, behaviour and communication. It shapes a child's attitude towards success, failures and behaviour and becomes an incentive for self-realisation and selfexpression.

The ability of self-esteem develops gradually; it is prone to alter and improve. Selfesteem developed improperly since childhood can become a reason for the loss of study motivation, development of complexes and feelings of inferiority and impotence. A child can lose confidence in his or her abilities, become anxious, irritable, aggressive or uncommunicative, vulnerable and indifferent towards own actions and mistakes.

The complexes acquired in childhood and low self-esteem can have negative consequences during teenage and adolescent years, considering that at this age a teenager or a young adolescent acts mostly independently and is outside parents' support. If we build a high self-esteem and self-respect in children, they can avoid many social and psychological problems in the future, becoming responsible, well-organised 
and independent individuals.

\section{References}

Baumeister, R. F., Campbell, J. D., Krueger, J. I., \& Vohs, K. D. (2003). Does high selfesteem cause better performance, interpersonal success, happiness, or healthier lifestyles? Psychological Science in the Public Interest, 4(1), 144. Retrieved March 25, 2021 from https://journals.sagepub.com/doi/pdf/10.1111/1529-1006.01431

Burnett, P. C. (1994). Self-concept and self-esteem in elementary schoolchildren. Psychology in the Schools, 31(2), 164-171.

Collins, M. (2009). Raising self-esteem in primary school: A whole school training programme. SAGE Publications.

Ghilay, Y., \& Ghilay, R. (2015). ISMS: A new model for improving student motivation and self-esteem in primary education. International Electronic Journal of Elementary Education, 7(3), 383-398. Retrieved March 28, 2021 from https://www.iejee.com/index.php/IEJEE/article/view/87

Gyurjinyan, D., \& Hekekyan, N. (2012). Mayreni 4. Hanrakrtakan dprotsi dasagirk (Native language $4^{\text {th }}$ grade. Secondary school textbook, in Armenian). Yerevan: Edit Print.

Mruk, C. (2006). Self-Esteem research, theory, and practice: Toward a positive psychology of self-esteem (3rd ed.). New York: Springer Publishing Company.

Orth, U., \& Robins, R. W. (2019). Development of self-esteem across the lifespan. In D. P. McAdams, R. L. Shiner, \& J. L. Tackett (Eds.), Handbook of personality development (pp. 328-344). New York: Guilford. Retrieved April $1, \quad 2021$ from https://www.researchgate.net/publication/329512803 Development of $\underline{\text { Self- }}$

Esteem Across the Lifespan/link/5c0be91d299bf139c74992c1/downlo $\underline{\mathrm{ad}}$

Rosenberg, M. (1979). Conceiving the self. New York: Basic Books. 